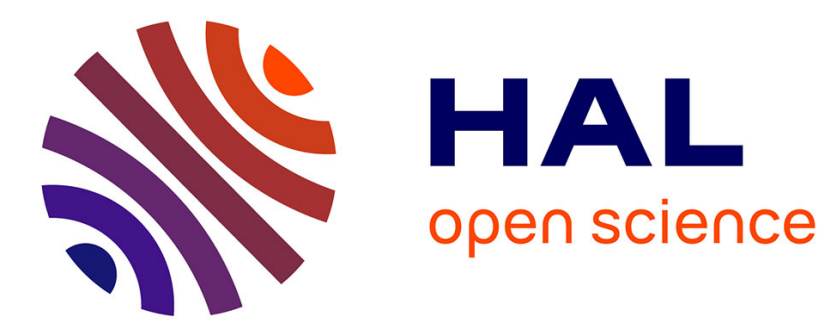

\title{
Separating Status from Power as an Antecedent of Intergroup Perception
}

\author{
Jennifer G. Boldry, Lowell Gaertner
}

\section{To cite this version:}

Jennifer G. Boldry, Lowell Gaertner. Separating Status from Power as an Antecedent of Intergroup Perception. Group Processes and Intergroup Relations, 2006, 9 (3), pp.377-400. 10.1177/1368430206064640 . hal-00571622

\section{HAL Id: hal-00571622 \\ https://hal.science/hal-00571622}

Submitted on 1 Mar 2011

HAL is a multi-disciplinary open access archive for the deposit and dissemination of scientific research documents, whether they are published or not. The documents may come from teaching and research institutions in France or abroad, or from public or private research centers.
L'archive ouverte pluridisciplinaire HAL, est destinée au dépôt et à la diffusion de documents scientifiques de niveau recherche, publiés ou non, émanant des établissements d'enseignement et de recherche français ou étrangers, des laboratoires publics ou privés. 


\title{
Separating Status from Power as an Antecedent of Intergroup Perception
}

\author{
Jennifer G. Boldry \\ Montana State University \\ Lowell Gaertner \\ University of Tennessee
}

\begin{abstract}
Status and power covary such that higher status groups are typically higher power groups. This research explored the effect of status on intergroup perception controlling for power. Experiment 1 manipulated the relative status of social groups and explicitly provided the groups equal power. Experiment 2 manipulated status and power orthogonally. Multiple measures yielded consistent patterns indicating that status affected perceived group centrality and variability independent of power. The patterns were consistent with a strategic intergroup comparison account as suggested by social identity theory. Specifically, the effect of status on intergroup perception varied with the relevance and valence of the dimension of comparison in a manner that balanced social reality with a positive social identity.
\end{abstract}

KEYWORDS group perception, group variability, heterogeneity, homogeneity, in-group homogeneity, ingroup homogeneity, intergroup perception, outgroup homogeneity, out-group homogeneity, power, status

RESEARCH on intergroup perception suggests that persons regard ingroups more favorably than outgroups (e.g. Brewer, 1979; Mullen, Brown, \& Smith, 1992) and perceive more variability among ingroup than outgroup members (Park \& Rothbart, 1982; Quattrone \& Jones, 1980). Intergroup perception, however, does not invariantly yield a more favorable and heterogeneous image of the ingroup. Indeed, research suggests that relative group status (e.g. Bettencourt, Dorr, Charlton, \& Hume, 2001) moderates intergroup perception such that members of higher status groups express stronger ingroup favoritism and perceive outgroup homogeneity, whereas members of lower status groups express less ingroup favoritism and perceive either ingroup homogeneity or equivalent variability within the ingroup and outgroup (Boldry \& Kashy, 1999; Lorenzi-Cioldi, 1998).

Social identity theory (SIT; Tajfel \& Turner, 1979) proposes that intergroup status is a motivating factor in intergroup perception because

\section{Author's note}

Address correspondence to Jennifer G. Boldry, Department of Psychology, 304 Traphagen Hall, Montana State University, Bozeman, MT 59717-3440, USA

[email: jennifer_boldry@yahoo.com] 
group membership is internalized as an aspect of the self that provides members with a social identity. Membership in a low status group can prove threatening because a positively valued social identity is derived primarily through favorable intergroup comparison. SIT outlines three strategies by which members of low status groups achieve a positively valued social identity. The lower status group can challenge the higher status group and reverse the status structure through social change. However, such social change can be difficult and, depending on the circumstances, might not be feasible (e.g. Ellemers, Van Knippenberg, \& Wilke, 1990). Alternatively, members of the low status group can choose the path of individual mobility, particularly when group boundaries are permeable, and seek inclusion in the higher status group (e.g. Ellemers, Van Knippenberg, De Vries, \& Wilke, 1988). A third possibility is a more strategic process in which group members engage in intergroup comparison on alternative social dimensions that are more favorable for the ingroup.

Research on the latter process suggests that strategic intergroup comparison is used rather flexibly, particularly on ambiguous dimensions that lack social consensus as to which group is superior. Such ambiguous dimensions are more amenable to motivated biases that distort perception and yield a favorable impression of the ingroup. Indeed, Ellemers, Van Rijswijk, Roefs, and Simons (1997) suggest that members of low status groups are 'likely to take consensually defined differences between the groups into account while displaying ingroup favoring biases with respect to more ambiguous aspects of the intergroup comparison' (p. 187). In regard to perceptions of group variability, data are relatively consistent with a strategic intergroup comparison process. Although Ellemers and Van Rijswijk (1997) did not compare the perceived variability of the ingroup to that of the outgroup, they reported that members of the low status group perceived more variability among ingroup members on dimensions relevant to the intergroup status structure than on dimensions irrelevant to the status structure. Enhancing the perceived heterogeneity of the ingroup on less desirable dimensions ostensibly softens the blow of intergroup comparison (e.g. 'we're not all bad'). Similarly, Rubin, Hewstone, and Voci (2001) compared perceptions of the relative variability of the ingroup and outgroup and reported stronger outgroup homogeneity (i.e. ingroup heterogeneity) on dimensions that threaten the ingroup's relative status. Such patterns are consistent with the possibility that intergroup status triggers a strategic social identity enhancement process that affects intergroup perception. Although members of low status groups are particularly apt to make strategic intergroup comparisons, the strategic comparison process is by no means limited to members of low status groups. Members of high status groups might also use strategic intergroup comparisons to maintain and bolster their group's relative social value. Indeed, research in the minimal group paradigm, in which groups ostensibly have equivalent status, frequently evidences such strategic intergroup comparisons in the form of ingroup-favoring ratings (Brewer, 1979).

\section{Is it status or power?}

Although previous research yields patterns consistent with SIT's account of status, a confound inherent in the extant data calls into question the role of status as an antecedent of intergroup perception. In particular, status (i.e. the social value of a person or group) and power (i.e. the ability to control or influence) covary in social environments such that groups higher in status tend also to be higher in power (e.g. Barth \& Noel, 1972; Carli \& Eagly, 1999; Guinote, Judd, \& Brauer, 2002; Hewstone, Rubin, \& Willis, 2002; Sidanius \& Pratto, 1999). The confluence of status and power most obviously affects studies that test status-effects among existing groups, such as those defined by gender (e.g. Bardach \& Park, 1996; LorenziCioldi, 1993), ethnicity (e.g. Cabecinhas \& Amancio, 1999), military rank (e.g. Boldry \& Kashy, 1999), or profession (Brown \& WoottenMillward, 1993). Also affected, however, are minimal group studies that manipulate status between novel groupings (e.g. Lorenzi-Cioldi, 
Deaux, \& Dafflon, 1998). Due to the typical confluence of status and power, members of minimal groups attribute higher power to the higher status group (e.g. Sachdev \& Bourhis, 1991). Consequently, effects conceptualized in terms of status may actually be consequences of power. Indeed, a growing literature has begun documenting the perceptual effects of relative group power.

Power, for example, indirectly affects intergroup perception by altering a group's actual behavioral diversity (Guinote et al., 2002). Because power ostensibly liberates persons from the constraints of social forces (e.g. norms, expectations) members of higher power groups can manifest a greater diversity of behaviors and are perceived to be more heterogeneous than are members of lower power groups. Consistent with such an account, participants who observed members of high and low power groups but were themselves neither affiliated with the groups nor aware of the power differential perceived more variability among the members of the high than low power group.

Power also directly affects perception by differentially altering the extent to which group members attend to the idiosyncratic characteristics of ingroup and outgroup members. Fiske and colleagues (Fiske, 1993; Fiske \& Depret, 1996; Neuberg \& Fiske, 1987) suggest that members of a lower power group, whose outcomes can be affected greatly by the actions of the higher power group, are apt to attend to the traits and attributes of the members of the higher power outgroup. On the other hand, members of the higher power group, whose outcomes are relatively impervious to the actions of the lower power group, have little reason to attend to and individuate members of the lower power outgroup. Such differential attention provides members of the lower power group with a more diverse and individuated perception of the outgroup.

Data from Sedikides (1997) offer an example of the inferential problem posed by the typical confluence of status and power. Based on SIT's upward mobility strategy, Sedikides (1997) predicted that members of low status permeable groups would be particularly apt to attend to the attributes of the higher status group to learn what it takes to 'become one of them'. Members of low and high status groups subsequently reviewed the names and alleged attributes of ingroup and outgroup members. Clustering patterns from a free recall task and confusion-errors from a name-to-attribute matching task revealed that members of high status groups individuated ingroup members more than outgroup members and members of low status groups individuated outgroup members more than ingroup members (also see Lorenzi-Cioldi et al., 1998). Such patterns are consistent with the predicted effect of status. However, the low and high status groups recruited in the research likely differed in regard to power (i.e. undergraduate vs. graduate students and freshmen vs. sophomores) and the observed patterns are consistent with the previously described power account offered by Fiske and colleagues.

\section{Why distinguish status from power?}

Distinguishing between relative group status and power is important because those constructs imply different mechanisms. Relative group status implies that social identity and esteem needs operate as antecedents of intergroup perception. Relative group power implies that the (in)ability to function freely of constraints operates as an antecedent of intergroup perception. Of course, status and power need not be mutually exclusive, such that both constructs can be involved in intergroup perception. Past research, however, has not successfully distinguished between the effects of status and power. The purpose of the current research is to test whether intergroup status affects intergroup perception independent of power.

\section{The current research}

To circumvent the inferential difficulty posed by the typical confluence of status and power, we manipulated the status of novel groups using the minimal group paradigm and explicitly provided the groups with equivalent power in 
an initial experiment and manipulated status orthogonal to power in an additional experiment. ${ }^{1}$

Sachdev and Bourhis (1991) unsuccessfully manipulated status orthogonal to power using minimal groups. They manipulated status by ostensibly assigning participants to groups based on a creativity test: one group consisted of creative persons and the other group consisted of uncreative persons. Participants subsequently performed an allocation task in which they allocated extra-credit points to ingroup and outgroup members. Sachdev and Bourhis manipulated power by informing participants prior to the allocation task that they would disregard the allocation decisions from members of one group (i.e. the no power group); a coin toss determined which group would not have power over the allocations. The flaw, in an otherwise inventive design, is that participants received ingroup and outgroup members' solutions to a second creativity test and were instructed to award credit points in a manner that reflected the creativity of the solutions. Unfortunately, the status manipulation undermined the power manipulation in that participants could infer that members of the high status (i.e. more creative) group would generate more creative solutions to the second test and, consequently, should receive more points. Indeed, manipulation checks revealed that the status manipulation increased the perceived power of the high vs. low status group. Despite attempts to independently manipulate status and power, participants attributed more power to the high status group. We avoided this problem by manipulating status and power on unrelated tasks.

We created a social context that was most appropriate for testing the plausibility of the strategic intergroup comparison account offered by SIT. We created groups with relatively impermeable boundaries to minimize attempts at upward mobility. To capture the strategic intergroup comparison process suggested by SIT, we assessed intergroup perception on three dimensions (established via pilot testing), each of which consisted of three positively valued and three negatively valued attributes. One dimension was relevant to the status hierarchy, a second dimension was relevant to the power hierarchy, and a third dimension was irrelevant to the status and power hierarchies. The latter irrelevant dimension provided an ambiguous dimension on which participants could evidence strategic intergroup perception and maintain perceptions favorable to their ingroup.

Following Kelley and Thibaut (1978), we operationalized power as the degree of control a group has over another group's outcomes (i.e. fate control) and employed two different manipulations of power across two experiments. We categorized participants into groups ostensibly on the basis of their artistic preferences (e.g. Tajfel, Billig, Bundy, \& Flament, 1971). We manipulated the relative status of the groups by providing false feedback regarding the relative performance of the ingroup and outgroup on a problem-solving task. To facilitate the power manipulations, participants were informed that their group would interact with the other group on a two-choice payoff matrix (i.e. similar to a Prisoner's Dilemma Matrix) and would earn money based on the interaction. Figure 1 displays the three matrices used across the experiments, the values of which were defined as the number of pennies available to each group member.

As described by Kelley and Thibaut (1978), we derived the outcome values in the matrices from three components of interdependence: reflexive control, fate control, and behavioral control. Reflexive control indexes the degree to which a group can directly affect its own outcome by varying between available behaviors (i.e. matrix choices). Fate control indexes the degree to which a group can directly affect the other group's outcome by varying between available choices. Behavioral control indexes the degree to which a group's outcomes are jointly influenced by its own choices in conjunction with the other group's choices. We held constant both reflexive control (fixed at 30 for both groups) and behavioral control (fixed at 0 for both groups) and varied fate control.

We assessed intergroup perception with measures of central tendency and variability. 
We assessed central tendency with mean ratings of the ingroup and outgroup. We assessed perceived variability among ingroup and outgroup members with measures typically employed for that purpose (e.g. Park \& Judd, 1990): percent estimate, range, and, additionally in Experiment 2 , similarity. ${ }^{2}$

\section{Stimulus development}

We conducted two pilot studies to obtain traits perceived as either relevant or irrelevant to the status and power dimensions. We subsequently used those traits in our primary experiments to assess intergroup perception.

Approximately 200 students in an undergraduate statistics class at Texas A\&M University (TAMU) participated in the first pilot study. An experimenter described the 'Lost on the Moon' task and payoff matrix task that we would use in the primary experiments to manipulate intergroup status and power. Participants generated and recorded the traits they deemed relevant and irrelevant to completing the status and power tasks, respectively.

Ninety-six students ( 48 males and 48 females) at TAMU participated in the second pilot study for partial credit in an introductory psychology course. The experimenter described the status and power tasks and distributed a list of the 109 traits generated in the first pilot study. Participants provided three ratings of each trait. Participants rated on 9-point scales $(1=$ not at all related; $9=$ very related) the extent to which each trait is relevant to the status and power tasks, respectively, and then rated the valence of each trait $(1=$ negative $; 9=$ positive $)$.

Based on the relevance and valence ratings we selected three traits that best reflected each of the six conditions formed by a factorial crossing of a trait's dimension (relevant to status, relevant to power, or irrelevant to status and power) and valence (positive or negative); yielding 18 traits in total. To represent the status dimension, we selected traits that received high relevance ratings for the status task and low relevance ratings for the power task. Three of those traits were rated as highly positive (survival skills, creative, and scientific) and three were rated as highly negative (unimaginative, inefficient, and gives-up-easily). To represent the power dimension, we selected traits that received high relevance ratings for the power task and low relevance ratings for the status task. Three of those traits were rated as highly positive (team player, cooperative, and agreeable) and three were rated as highly negative (selfish, greedy, and manipulative). To represent the irrelevant dimension, we selected traits that received low relevance ratings for both the status and power tasks. Three of those traits were rated as highly positive (funny, athletic, and happy) and three were rated as highly negative (dull, grumpy, and shallow). Participants in the subsequent experiments rated the central tendency and variability of the ingroup and outgroup on those 18 traits.

\section{Experiment 1}

We differentiated status from power by manipulating the relative status of the ingroup and outgroup in situations in which the groups had equal power. In the independent condition, neither group could influence the outcome of the other group and, consequently, neither group had power. In the interdependent condition, both groups could affect the other group's outcomes by the same degree and, consequently, both groups had the same degree of power. Such a manipulation reflects Fiske and colleagues' (Fiske, 1993; Neuberg \& Fiske, 1987) distinction between conditions of outcome independence and interdependence. As we discussed previously, Fiske and colleagues suggest that power affects intergroup perception by motivating persons to attend to the traits and attributes of members of those outgroups who have power over the ingroup.

Consequently, this experiment enables a test of whether status affects intergroup perception independently of power by creating a hierarchical intergroup status structure (high vs. low) in a situation in which neither group has power over the other (i.e. independent condition) and a situation in which each group has power over the other (i.e. interdependent condition). If the effect of status on intergroup 
perception is an artifact of its typical confluence with power (or operates only in the context of a power structure), status and power will interact such that the hypothesized pattern of the status effect (described subsequently) will occur in the interdependent condition in which groups have power, but will be negated in the independent condition in which groups lack power. On the other hand, if status affects intergroup perception independently of power, the hypothesized status effect will occur equally across levels of the interdependence manipulation (i.e. will not be moderated by the presence vs. absence of intergroup power).

As we described previously, we created a social context using minimal groups that enabled a test of the strategic intergroup comparison process as described by SIT. The low and high status groups had relatively impermeable boundaries. Likewise, aside from the information about the relative status of the groups, group members did not receive additional information about the idiosyncratic characteristics of other ingroup and outgroup members. If a strategic process biases intergroup perception in a manner that maintains or enhances a group's social value, the effect of status on intergroup perceptions should be moderated by the valence and relevance of the dimension of intergroup comparison. In particular, the strategic intergroup comparison process described by SIT predicts a Status $\times$ Group (ingroup vs. outgroup) $\times$ Relevance $\times$ Valence interaction.

Members of high and low status groups will acknowledge the established superiority of the high status group on attributes relevant to the status dimension. On the measure of central tendency, members of both groups will consider the positively valued status traits to be more descriptive of the high than the low status group and the negatively valued status traits to be more descriptive of the low than high status group. On the variability measures, members of both groups will perceive relatively less variability among members of the high status group on the positive status traits and relatively less variability among members of the low status group on the negative status traits. In other words, members of the high status group will perceive ingroup homogeneity on the positive status traits and outgroup homogeneity on the negative status traits and members of the low status group will perceive outgroup homogeneity on the positive status traits and ingroup homogeneity on the negative status traits.

However, members of the low status group (and possibly the high status group) will capitalize on the irrelevant traits to enhance their group's social value. On the measure of central tendency, members of the low (and possibly high) status group will consider the positive irrelevant traits to be relatively more descriptive of their ingroup and the negative irrelevant traits to be relatively more descriptive of outgroup members. On the variability measures, members of the low (and possibly high) status group will perceive ingroup homogeneity on the positive irrelevant traits and outgroup homogeneity on the negative irrelevant traits. Across the status and irrelevant traits, for example, the intergroup perception held by members of the low status group might reflect, 'they are all more creative than we are, but we are all more athletic than they are'. Our predictions do not address the power relevant traits and we assessed perception on those traits for exploratory purposes.

In sum, the design is a 2 (status) $\times 2$ (interdependence) $\times 2$ (group: ingroup, outgroup) $\times 3$ (trait relevance: relevant to status, relevant to power, irrelevant to status and power) $\times$ 2(trait valence: positive, negative) mixed factorial, with the latter three factors being within-subject and group coding whether a trait is rated in regard to the ingroup or outgroup. Such a design enables a test of the predicted pattern derived from SIT regarding members' of high and low status groups perception of the ingroup vs. outgroup on a given dimension of social comparison as defined by a trait's relevance and valence. We can assess, for example, whether members of low status groups strategically enhance their social identity by perceiving less variability among ingroup than outgroup members (i.e. ingroup homogeneity) on positive traits that are irrelevant to the status structure (e.g. 'we are all more 
athletic than they are'). Importantly, the design distinguishes status from power and tests whether the predicted pattern is moderated by intergroup power (i.e. interdependence).

\section{Method}

Participants and design Altogether 232 students (116 females and 116 males) at TAMU participated for partial credit in an introductory psychology class. To manipulate relative status, we provided participants with false feedback regarding the relative performance of the ingroup and outgroup on the 'Lost on the Moon' task (Hall, 1971), which required participants to rank order 15 items in terms of their importance for survival on the moon. To provide an anchor point against which numeric feedback could be assessed, participants were informed that a score of 50 is considered acceptable or 'passing'. To further enhance the importance of the task, feedback indicated that successful performance on the moon task is associated with academic and career success. Participants in the high status condition were informed that members of their artistic preference group typically perform better than do members of the other group and, in the current session, their group scored a 70 and the other group scored only a 30 . Participants in the low status condition were informed that members of their artistic preference group typically perform worse than do members of the other group and that, in the current session, their group scored only a 30 and the other group scored a 70 .

To manipulate outcome independence versus interdependence participants anticipated interacting with the other group on one of two matrices (see Figure 1; the matrix values indicate the amount of pennies that would be received by each group member). The high and low status group had equal power (i.e. fate

Independent and Interdependent Matrices of Experiment 1
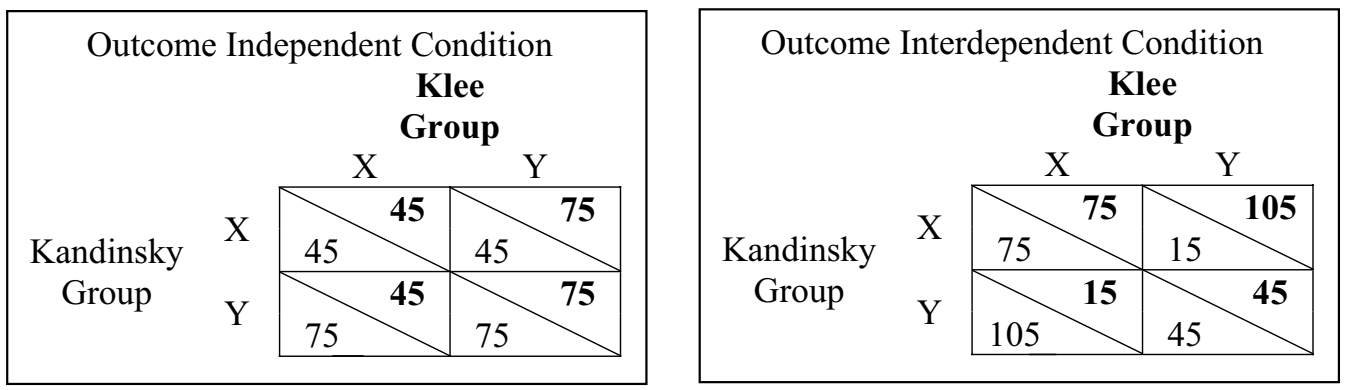

Relative Power Matrix for Experiment 2

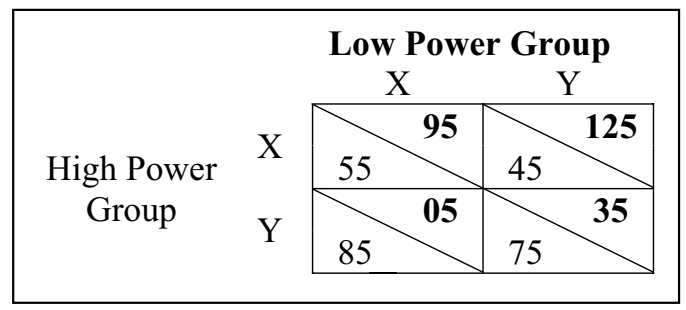

Figure 1. Matrices used in Experiments 1 and 2.

The terms 'Low Power' and 'High Power' are displayed for didactic purposes in the matrices of Experiment 2 and were replaced with the relevant group names (i.e. Klee and Kandinsky) in the actual experiments. 
control) on both matrices. On the outcome independent matrix, neither group could affect the other group's outcomes-both groups had a fate control of 0 . On the outcome interdependent matrix, both groups could affect the other group's outcome by US $\$ 0.60$-both groups had a fate control of 60 . We fixed reflexive and behavioral control at 30 and 0 , respectively for both groups on both matrices. We counterbalanced the order in which participants experienced the status and outcome dependence manipulations.

Procedure and dependent measures Students participated in six-person same-sex sessions and sat at separate computer cubicles. Participants initially completed a computerized painting preference task in which they viewed 10 pairs of paintings and indicated the painting in each pair they preferred (e.g. Tajfel et al., 1971). Feedback informed participants that one painting in each pair was a work by the artist Klee and one was a work by the artist Kandinsky. To hold constant relative group size, participants were informed that half of the college student population preferred Klee and half preferred Kandinsky and three persons in the current session belonged to the group of people who prefer Klee and three belonged to the group of people who prefer Kandinsky. Feedback informed participants that they were assigned to the Klee group on the basis of their artistic preferences.

Participants subsequently completed the 'Lost on the Moon' task and received information about the pending intergroup interaction on the payoff matrix, the order of which was counterbalanced across participants. Participants individually completed the moon task on the computer and were informed that the computer would score their solution and aggregate their score with the scores of the other two members of their group to calculate a group score. Participants received either low or high status feedback and completed a brief exercise to ensure that they understood the feedback.

Instructions to the matrix task indicated that the two groups would interact on a payoff matrix and members of both groups would receive money based on the joint decisions of both groups. In particular, instructions indicated that each group would select a choice on the matrix (either $\mathrm{X}$ or $\mathrm{Y}$ ) and the decisions would be made simultaneously, so neither group would know what choice was selected by the other group until both groups had made their decision. Participants were further informed that each group member would privately select their preferred decision for their group and the group's final decision would be determined by a majority rule. Participants completed a brief exercise to ensure that they understood the matrix (e.g. "how much money will your group receive if your group selects " $\mathrm{X}$ " and the other group selects "Y"?').

Computerized instructions indicated that the groups would interact on the payoff matrix after participants answered a series of questions. Those questions constituted the dependent measures and consisted of assessments of intergroup perception and manipulation checks.

Measures of intergroup perception For each of the 18 traits, participants completed a mean rating, percent estimate, and range measure for the ingroup and outgroup, respectively. We randomly varied across participants the order in which the three measures were completed. We randomly varied across measures the presentation order of the 18 traits and the order in which participants rated the ingroup and outgroup.

For the mean measure, participants rated on a 7 -point scale $(1=$ not at all; $7=$ very much $)$ the degree to which a given trait described, on average, the members of the group. For the percent estimate task, participants indicated the percentage of group members $(0-100)$ who possess a given trait. For the range task, participants indicated on a 7 -point scale ( $1=$ not at all; $7=$ very much) the score that reflected the member of the group who most possessed the given trait and the score that reflected the member of the group who least possessed the given trait. The absolute value of the difference between the latter two ratings provided an assessment of perceived range. 
Manipulation checks As a check for the status manipulation, participants indicated on 7-point scales $(1=$ not at all and $7=$ very much $)$ the degree to which: (a) their group performed better than the other group on the moon task; (b) their group is better than the other group in terms of problem solving ability; (c) the other group performed better than their group on the moon task; and (d) the other group is better than their group in terms of problem solving ability. We averaged the first two items to assess the perceived status of the ingroup and averaged the latter two items to assess the perceived status of the outgroup, with the difference between the ingroup and outgroup indices indicating perceptions of relative status.

As a check for the outcome dependence manipulation, participants indicated on 7-point scales ( $1=$ not at all; $7=$ very much $)$ the extent to which: (a) their group could influence the earnings of the other group; (b) their group could influence the earnings of the other group by choosing $\mathrm{X}$ instead of $\mathrm{Y}$; (c) the other group could influence the earnings of their group; and (d) the other group could influence the earnings of their group by choosing $\mathrm{X}$ instead of $\mathrm{Y}$. We averaged the first two items to assess the perceived power of the ingroup and averaged the latter two items to assess the perceived power of the outgroup.

Participants completed the measures of intergroup perception prior to the manipulation checks. The ordering of the status and outcome dependence checks was counterbalanced and the ordering of their respective items varied randomly. Participants subsequently indicated whether they thought they were assigned to the wrong artistic preference group. The experimenter then debriefed and thanked the participants.

\section{Results}

Approximately 13\% ( $n=32)$ of the participants thought they were assigned to the wrong artistic preference group. We excluded those participants from the analyses because we could not discern which group served as their ingroup. We analyzed the responses of the remaining 200 participants (100 males and 100 females).
Manipulation checks We entered the ratings of perceived status and power into separate 2 (ingroup status: high, low) $\times 2$ (outcome dependence: independent, interdependent) $\times$ 2 (sex) $\times 2$ (group: ingroup, outgroup) multivariate analyses of variance (ANOVAs). The latter variable, group, served as a withinsubjects factor that coded whether judgments were made of the ingroup or outgroup, respectively.

Intergroup status A Group $\times$ Status effect $(F(1$, $192)=384.99, p<.01)$, confirmed our manipulation of relative status. Members of the high status group perceived the ingroup $(M=5.13$, $S D=1.32)$ as having higher status than the outgroup $(M=2.13, S D=1.03)(F(1,107)=$ $249.71, p<.01)$. Members of the low status groups perceived the ingroup $(M=2.59, S D=$ 1.04) as having lower status than the outgroup $(M=4.95, S D=1.38)(F(1,91)=141.56, p<$ $.01)$. No other effects influenced the perceived relative status of the ingroup and outgroup.

Intergroup outcome dependence An outcome dependence main effect $(F(1,192)=392.33$, $p<.01)$, confirmed our manipulation of intergroup dependence. Participants perceived the groups (both ingroup and outgroup) as having more power in the interdependent condition $(M=5.57, S D=1.13)$ than in the independent condition $(M=1.87, S D=1.48)$. The absence of effects involving the within-subjects group variable indicated that, as intended, participants did not perceive power differences between the ingroup and outgroup. Aside from a main effect of sex, indicating that females perceived more power than males, no other effects influenced perceived power.

Measures of intergroup perception We formed ingroup and outgroup indices of the mean, percent estimate, and range measures by averaging across the three traits in each of the six (relevance by valence) cells for the ingroup and outgroup, respectively. We entered the indices into separate 2 (status) $\times 2$ (dependence) $\times 2(\operatorname{sex}) \times 2$ (group: ingroup, outgroup $) \times 3$ (relevance: relevant to status, 
relevant to power, irrelevant to status and power $) \times 2$ (valence: positive, negative) multivariate ANOVAs, with repeated measures on the last three factors. The mean and percent estimate measures revealed the predicted Status $\times$ Group $\times$ Relevance $\times$ Valence four-way interaction, which was not moderated by interdependence.

Mean measure The predicted Status $\times$ Group $\times$ Relevance $\times$ Valence four-way interaction was significant $(F(2,191)=31.68, p<.01)$. The top panel of Table 1 displays the relevant means. We decomposed the four-way interaction by testing the Group $\times$ Relevance $\times$ Valence effect in levels of status. The simple three-way interaction was significant for both the high status group $(F(2,106)=17.64, p<$ $.01)$, and the low status group $(F(2,90)=15.27$, $p<.01)$.

For the high status group, the Group $\times$ Valence interaction was significant for the status traits $(F(1,107)=109.05, p<.01)$, power traits $(F(1,107)=48.84, p<.01)$, and irrelevant traits $(F(1,107)=57.03, p<.01)$. Tests of the group effect in levels of valence indicated that members of the high status group considered the ingroup relative to the outgroup to be better described by the positive status traits $(F(1,107)=107.90, p<.01)$, positive power traits $(F(1,107)=60.50, p<.01)$, and positive irrelevant traits $(F(1,107)=50.43, p<.01)$, whereas they considered the outgroup relative to the ingroup to be better described by the negative status traits $(F(1,107)=81.12, p<.01)$, negative power traits $(F(1,107)=22.34, p<$ $.01)$, and negative irrelevant traits $(F(1,107)=$ $46.50, p<.01)$.

For the low status group, the Group $\times$ Valence interaction was marginally significant for the status traits $(F(1,91)=3.66, p=.06)$, and significant for the irrelevant traits $(F(1,91)$ $=21.87, p<.01)$. Tests of the group effect in levels of valence indicated that members of the low status group acknowledged the status differential and considered the outgroup relative to the ingroup to be better described by the positive status traits $(F(1,91)=11.58, p<.01)$. Concurrently, however, they evidenced a strategic process of intergroup comparison on the irrelevant traits by rating the positive irrelevant traits as more descriptive of the ingroup than

Table 1. Mean intergroup perception (and standard deviations) for Experiment 1 by measure as a function of status, group, relevance, and valence

\begin{tabular}{|c|c|c|c|c|c|c|}
\hline \multirow[b]{2}{*}{ Status } & \multicolumn{2}{|c|}{ Status relevant } & \multicolumn{2}{|c|}{ Power relevant } & \multicolumn{2}{|c|}{ Irrelevant } \\
\hline & Positive & Negative & Positive & Negative & Positive & Negative \\
\hline \multicolumn{7}{|l|}{ Mean measure } \\
\hline \multicolumn{7}{|l|}{ High status } \\
\hline Ingroup & $5.17(0.94)$ & $2.58(0.89)$ & $5.31(0.86)$ & $3.11(1.02)$ & $5.01(0.78)$ & $2.77(0.79)$ \\
\hline Outgroup & $3.58(1.02)$ & $3.90(1.17)$ & $4.26(1.05)$ & $3.68(1.01)$ & $4.23(0.86)$ & $3.52(1.00)$ \\
\hline \multicolumn{7}{|l|}{ Low status } \\
\hline Ingroup & $4.50(0.96)$ & $2.92(0.97)$ & $4.98(0.98)$ & $3.15(1.02)$ & $4.86(0.84)$ & $2.67(1.02)$ \\
\hline Outgroup & $4.98(0.97)$ & $2.96(0.98)$ & $4.99(0.83)$ & $3.43(1.12)$ & $4.43(0.84)$ & $3.07(1.06)$ \\
\hline \multicolumn{7}{|c|}{ Percent estimate measure } \\
\hline \multicolumn{7}{|l|}{ High status } \\
\hline Ingroup & $67.34(14.55)$ & $25.23(13.43)$ & $71.05(13.95)$ & $33.72(17.85)$ & $63.69(14.84)$ & $26.41(13.45)$ \\
\hline Outgroup & $43.15(16.15)$ & $41.99(18.62)$ & $57.98(16.97)$ & $37.84(18.17)$ & $54.53(14.83)$ & $35.88(17.64)$ \\
\hline \multicolumn{7}{|l|}{ Low status } \\
\hline Ingroup & $54.16(15.82)$ & $30.00(14.59)$ & $65.73(17.22)$ & $33.45(16.97)$ & $60.27(13.56)$ & $25.27(16.26)$ \\
\hline Outgroup & 63.53(13.68) & $29.45(15.80)$ & $66.33(12.87)$ & $35.50(16.73)$ & $54.95(14.62)$ & $30.63(16.65)$ \\
\hline
\end{tabular}

Notes: Standard deviations are in parentheses. Sample size is 108 for high status and 92 for low status. Higher numbers indicate that a given trait is perceived to be (a) more descriptive of the group for the mean measure, and (b) perceived to be possessed by a greater percentage of group members for the percent estimate measure. 
the outgroup $(F(1,91)=22.41, p<.01)$, and the negative irrelevant traits as more descriptive of the outgroup than the ingroup $(F(1,91)=$ $13.09, p<.01)$.

Percent estimate measure The predicted Status $\times$ Group $\times$ Relevance $\times$ Valence four-way interaction was significant $(F(2,191)=44.45, p<$ .01 ), which was similar in form to the interaction detected on the mean measure. The bottom panel of Table 1 displays the relevant means. The Group $\times$ Relevance $\times$ Valence effect was significant for both the high status group $(F(2,106)=28.49, p<.01)$, and the low status group $(F(2,90)=20.67, p<.01)$.

For the high status group, the Group $\times$ Valence interaction was significant for the status traits $(F(1,107)=128.21, p<.01)$, power traits $(F(1,107)=30.13, p<.01)$, and irrelevant traits $(F(1,107)=45.95, p<.01)$. Tests of the group effect in levels of valence indicated that members of the high status group perceived that a greater percentage of ingroup than outgroup members possessed the positive status traits $(F(1,107)=138.35, p<.01)$, positive power traits $(F(1,107)=52.52, p<.01)$, and positive irrelevant traits $(F(1,107)=35.42, p<$ $.01)$. On the other hand, they perceived that a greater percentage of outgroup than ingroup members possessed the negative status traits $(F(1,107)=71.66, p<.01)$, negative power traits $(F(1,107)=5.34, p<.05)$, and negative irrelevant traits $(F(1,107)=39.53, p<.01)$.

For the low status group, the Group $\times$ Valence interaction was significant for the status traits $(F(1,91)=9.81, p<.01)$ and irrelevant traits $(F(1,91)=25.20, p<.01)$. Tests of the group effect in levels of valence indicated that members of the low status group acknowledged the status difference and perceived a greater percentage of outgroup than ingroup members possessed the positive status traits $(F(1,91)=$ $20.88, p<.01)$. At the same time, they evidenced a strategic process of intergroup comparison and perceived the positive irrelevant traits to be possessed by a greater percentage of ingroup than outgroup members $(F(1,91)=$ $16.38, p<.01)$, and the negative irrelevant traits to be possessed by a greater percentage of outgroup than ingroup members $(F(1,91)=$ $18.11, p<.01)$.

Range measure The pattern of response to the range measure differed from the patterns on the previous measures. The predicted Group $\times$ Relevance $\times$ Valence $\times$ Status four-way interaction was not significant $(F(2,158)=1.73, n s)$ and, instead, was qualified by the five-way interaction involving sex $(F(2,158)=3.82, p<$ $.05)$ (See Table 2). We decomposed the interaction by testing the predicted four-way interaction separately for males and females. The four-way interaction was significant for males $(F(2,82)=4.65, p<.05)$ but not females $(F(2$, $79)=.74, n s)$.

Decomposition of the four-way interaction for males revealed that the pattern differed from the predicted pattern. In particular, the Group $\times$ Relevance $\times$ Valence three-way was significant in the low status condition $(F(2,37)$ $=4.10, p<.05)$ but not the high status condition $(F(2,44)=1.69, n s)$. In the low status condition, the Group $\times$ Valence effect was significant on the power traits $(F(1,41)=6.61, p$ $<.05)$ and the irrelevant traits $(F(1,42)=7.12$, $p<.01)$. Pairwise comparisons revealed differential perception of the ingroup and outgroup on only the positive irrelevant traits $(F(1,45)=$ $4.39, p<.05)$. Keeping in mind that higher values indicate greater variability, male members of low status groups perceived a greater range among ingroup than outgroup members. This pattern of perception is exactly opposite to predictions and the patterns detected on the previous measures, in that results for the range reflect outgroup (not ingroup) homogeneity on positive irrelevant traits.

\section{Discussion}

We differentiated status from power by explicitly equating the groups in terms of power and manipulating status in contexts in which both groups could affect the other group's outcomes (interdependent context) or not (independent context). In both contexts, the groups differed in status but were equivalent in power (as our manipulation checks confirmed). 
Table 2. Mean range perception (and standard deviations) in Experiment 1 as a function of group, valence, relevance, status, and sex

\begin{tabular}{|c|c|c|c|c|c|c|}
\hline \multirow[b]{2}{*}{ Status } & \multicolumn{2}{|c|}{ Status relevant } & \multicolumn{2}{|c|}{ Power relevant } & \multicolumn{2}{|c|}{ Irrelevant } \\
\hline & Positive & Negative & Positive & Negative & Positive & Negative \\
\hline \multicolumn{7}{|l|}{ Males } \\
\hline \multicolumn{7}{|l|}{ High status } \\
\hline Ingroup & $3.75(0.95)$ & $3.62(1.16)$ & $3.75(1.10)$ & $3.81(1.07)$ & $4.01(1.05)$ & $3.54(1.01)$ \\
\hline Outgroup & $3.78(1.04)$ & $3.83(0.97)$ & $3.86(1.02)$ & $3.70(0.95)$ & $3.92(1.13)$ & $3.57(1.05)$ \\
\hline \multicolumn{7}{|l|}{ Low status } \\
\hline Ingroup & $4.27(0.94)$ & $4.10(1.08)$ & $4.07(1.16)$ & $3.76(1.12)$ & $4.37(1.10)$ & $3.74(1.08)$ \\
\hline Outgroup & $4.07(1.23)$ & $3.79(1.24)$ & $3.86(1.24)$ & $3.87(1.29)$ & $4.15(1.24)$ & $3.92(1.36)$ \\
\hline \multicolumn{7}{|l|}{ Females } \\
\hline \multicolumn{7}{|l|}{ High status } \\
\hline Ingroup & $4.14(0.86)$ & $3.86(0.86)$ & $4.28(1.10)$ & $4.08(1.15)$ & $4.33(1.14)$ & $3.83(1.06)$ \\
\hline Outgroup & $4.06(0.92)$ & $3.99(1.01)$ & $4.14(1.07)$ & $4.09(1.18)$ & $4.23(1.02)$ & $4.03(1.10)$ \\
\hline \multicolumn{7}{|l|}{ Low status } \\
\hline Ingroup & $4.14(1.06)$ & $3.90(1.13)$ & $3.93(1.13)$ & $3.79(1.05)$ & $4.05(1.20)$ & $3.71(0.94)$ \\
\hline Outgroup & $3.88(1.08)$ & $3.81(0.98)$ & $3.83(1.08)$ & $3.77(1.11)$ & $4.10(1.09)$ & $3.73(1.00)$ \\
\hline
\end{tabular}

Notes: Standard deviations are in parentheses. Due to some missing data, sample size varies from 52-54 for high status males, 44-46 for low status males, 52-54 for high status females, and 42-46 for low status females. Higher numbers indicate a greater perceived range among group members.

We created a context sensitive to the strategic process of intergroup comparison, as described by SIT, by assessing intergroup perception on dimensions relevant and irrelevant to status and power. The irrelevant dimension provided members of the low (and high) status group with an ambiguous arena in which they could construct intergroup comparisons that yield a positively distinct social identity. Both the mean and percent estimate measures revealed the Status $\times$ Group $\times$ Relevance $\times$ Valence interaction predicted by SIT and that effect was not moderated by interdependence.

Members of low and high status groups acknowledged the established status hierarchy on the positive status traits. Members of both groups considered the positive status traits to be more descriptive of and possessed by a greater percentage of members of the high than low status group. Interestingly, only members of the high status group acknowledged the status difference on the negative status traits and perceived the negative status traits as more descriptive of and possessed by a greater percentage of outgroup than ingroup members.
As expected in regard to the potential for a strategic process of intergroup comparison, members of the low and high status groups capitalized on the irrelevant traits to maintain the positive value of the ingroup. Members of both groups perceived the positive irrelevant traits to be more descriptive of and possessed by a greater percentage of ingroup than outgroup members. Likewise, they perceived the negative irrelevant traits to be more descriptive of and possessed by a greater percentage of outgroup than ingroup members.

We did not offer predictions for intergroup perception on the power traits. Nonetheless, both the mean and percent estimate measures revealed that only members of the high status group evidenced differential intergroup perception on the power traits. Members of the high status group perceived positive power traits to be more descriptive of and possessed by a greater percentage of ingroup than outgroup members, whereas they perceived negative power traits to be more descriptive of and possessed by a greater percentage of outgroup than ingroup members. Members of the low status group did not differentially perceive the ingroup and 
outgroup on the power traits. Given our lack of predictions for the power traits, we withhold interpretation until determining whether those patterns replicate in the remaining experiment.

Unlike the mean and percent estimate, the range did not yield patterns consistent with a strategic process of motivated intergroup comparison. Perceived variability as assessed by the range varied as a function of group, valence, and relevance, but only for male members of low status groups. Furthermore, the pattern of variation was opposite to predictions. Males in low status groups perceived a greater range among ingroup than outgroup members on positive irrelevant traits.

As a final issue, it is possible that the percent estimate measure tapped into perceptions of central tendency rather than perceived variability. The minimal group procedure that we employed to unconfound intergroup status from power required us to use the percent estimate measure in a manner different than it is typically used to assess variability. Participants typically rate the percentage of group members who possess stereotype consistent and inconsistent traits and the difference between the latter percentages provides an estimate of the extent to which a group is perceived to match homogeneously the stereotype. Because there are no pre-existing stereotypes of minimal groups, we had participants rate the percentage of group members who possessed the status, power, and irrelevant traits. Consequently, in the current research, the percent estimate task may share more in common with the measure of central tendency (e.g. the mean) than measures of variability. ${ }^{3}$ To obtain an additional measure of perceived variability, we include a measure of perceived similarity in Experiment 2.

\section{Experiment 2}

In the previous experiment, we provided the low and high status groups with equivalent power. In the current experiment, we methodologically distinguished status from power by manipulating a group's relative status orthogonal to its relative power. We again fostered a social context sensitive to the strategic inter- group comparison mechanism and included perceived similarity as an additional measure of variability.

\section{Method}

Altogether, 321 students (158 females and 163 males) at Montana State University participated for partial credit in an introductory psychology class. The procedure and dependent measures were identical to those of Experiment 1 with the exception of the manipulation of relative power and the addition of a measure of perceived trait similarity. We used a 2(relative ingroup status: low, high) $\times 2$ (relative ingroup power: low, high) between-subjects factorial design. We manipulated status as we did in the previous experiment and manipulated power with a single intergroup payoff matrix (see Figure 1). The low power group could affect the outcomes of the high power group by US $\$ 0.10$ (i.e. fate control for the low power group $=10$ ) and the high power group could affect the outcomes of the low power group by US $\$ 0.90$ (i.e. fate control for the high power group $=90$ ). Again, both groups had reflexive control of 30 and behavioral control of 0 . Aside from the variation in manipulated power, the procedure was identical to that of Experiment 1.

For the trait-similarity measure, participants rated the members of the ingroup and outgroup, respectively, on 7-point scales $(1=$ not at all similar; $7=$ very similar) in terms of how similar they are in regard to each of the 18 traits (e.g. 'to what degree are all members of the Klee Group similar in terms of creativity?'). As in Experiment 1, we counterbalanced the order in which the independent variables were manipulated, randomized across participants the presentation order of the measures of intergroup perception, and randomized across measures the ordering of the 18 traits and the order in which participants rated the ingroup and outgroup.

\section{Results}

Approximately 7\% ( $n=23)$ of the participants thought they were assigned to the wrong artistic preference group. We excluded those participants from the analyses because we could not 
discern which group served as their ingroup. We analyzed the responses of the remaining 298 participants (149 females and 149 males).

Manipulation checks We entered the ratings of perceived status and power into separate 2 (ingroup status: low, high) $\times 2$ (ingroup power: low, high $) \times 2($ sex $) \times 2$ (group: ingroup, outgroup) multivariate ANOVAs. The latter variable, group, served as a within-subjects factor that coded whether judgments were made of the ingroup or outgroup, respectively.

Intergroup status A Group $\times$ Status effect $(F(1$, $287)=702.59, p<.01)$ confirmed our manipulation of relative group status: members of the high status group perceived the ingroup ( $M=$ $5.35, S D=1.14)$ as having higher status than the outgroup $(M=2.20, S D=.92)(F(1,147)=$ $478.53, p<.01)$. Members of the low status groups perceived the ingroup $(M=2.64, S D=$ $1.11)$ as having lower status than the outgroup $(M=4.97, S D=1.18)(F(1,146)=224.99, p<$ $.01)$. A Group $\times$ Status $\times$ Sex effect $(F(1,287)$ $=4.01, p<.05)$, indicated that the Group $\times$ Status effect, which was significant and of the same form for males and females, was stronger for males. No other effects influenced the perceived relative status of the ingroup and outgroup.

Intergroup power A Group $\times$ Power effect $(F(1$, $287)=294.84, p<.01)$, confirmed our manipulation of relative group power. Members of the high power group perceived the ingroup as having more power $(M=5.41, S D=1.20)$ than the outgroup $(M=3.60, S D=1.31)(F(1,147)$ $=126.44, p<.01)$. Members of the low power group perceived the ingroup as having less power $(M=3.43, S D=1.30)$ than the outgroup $(M=5.59, S D=1.16)(F(1,146)=173.67, p<$ $.01)$. No other effects influenced the perceived relative power of the ingroup and outgroup.

Measures of intergroup perception We formed ingroup and outgroup indices of the mean, percent estimate, similarity, and range measures by averaging across the three traits in each of the six (relevance by valence) cells for the ingroup and outgroup, respectively. We entered those indices into separate 2 (status) $\times$ 2 (power) $\times 2($ sex $) \times 2$ (group: ingroup, outgroup) $\times 3$ (relevance: relevant to status, relevant to power, irrelevant to status and power) $\times 2$ (valence: positive, negative) multivariate ANOVAs, with repeated measures on the last three factors. The mean, percent estimate, and similarity measures revealed the predicted Status $\times$ Group $\times$ Relevance $\times$ Valence fourway interaction, which was similar in form to the four-way interactions detected in the previous experiments and was not moderated by relative power.

Mean measure The predicted Status $\times$ Group $\times$ Relevance $\times$ Valence four-way interaction was significant $(F(2,289)=57.48, p<.01)$. The top panel of Table 3 displays the relevant means. The Group $\times$ Relevance $\times$ Valence effect was significant for both the high status group $(F(2,147)=29.74, p<.01)$ and the low status group $(F(2,147)=28.75, p<.01)$.

For the high status group, the Group $\times$ Valence interaction was significant for the status traits $(F(1,148)=172.37, p<.01)$, power traits $(F(1,148)=38.20, p<.01)$, and irrelevant traits $(F(1,148)=48.11, p<.01)$. Tests of the group effect in levels of valence indicated that members of the high status group considered the ingroup relative to the outgroup to be better described by the positive status traits $(F(1,148)=166.91, p<.01)$, positive power traits $(F(1,148)=52.64, p<.01)$, and positive irrelevant traits $(F(1,148)=42.24, p<.01)$. Whereas they considered the outgroup relative to the ingroup to be better described by the negative status traits $(F(1,148)=108.94, p<$ $.01)$, negative power traits $(F(1,148)=11.44$, $p<.01)$, and negative irrelevant traits $(F(1,148)$ $=40.59, p<.01)$. Members of the high status group considered the positive traits (of all dimensions) to be more descriptive of the ingroup and the negative traits (of all dimensions) to be more descriptive of the outgroup.

For the low status group, the Group $\times$ Valence interaction was significant for the status traits $(F(1,148)=28.14, p=.01)$ and irrelevant traits $(F(1,148)=19.26, p<.01)$. Tests of 
Table 3. Mean intergroup perception (and standard deviations) for Experiment 2 by measure as a function of status, group, relevance, and valence

\begin{tabular}{|c|c|c|c|c|c|c|}
\hline \multirow[b]{2}{*}{ Status } & \multicolumn{2}{|c|}{ Status relevant } & \multicolumn{2}{|c|}{ Power relevant } & \multicolumn{2}{|c|}{ Irrelevant } \\
\hline & Positive & Negative & Positive & Negative & Positive & Negative \\
\hline \multicolumn{7}{|l|}{ Mean measure } \\
\hline \multicolumn{7}{|l|}{ High status } \\
\hline Ingroup & $5.30(1.40)$ & $2.55(1.02)$ & $5.24(1.01)$ & $3.19(1.22)$ & $4.92(1.02)$ & $2.74(1.09)$ \\
\hline Outgroup & $3.54(1.17)$ & $3.71(1.15)$ & $4.35(1.24)$ & $3.55(1.28)$ & $4.29(1.00)$ & $3.42(1.29)$ \\
\hline \multicolumn{7}{|l|}{ Low status } \\
\hline Ingroup & $4.29(1.24)$ & $2.96(1.11)$ & $4.81(1.21)$ & $3.06(1.29)$ & $4.73(1.01)$ & $2.70(1.10)$ \\
\hline Outgroup & $5.19(1.03)$ & $2.87(1.04)$ & $5.03(0.99)$ & $3.26(1.21)$ & $4.38(0.99)$ & $3.04(1.18)$ \\
\hline \multicolumn{7}{|c|}{ Percent estimate measure } \\
\hline \multicolumn{7}{|l|}{ High status } \\
\hline Ingroup & $70.20(17.12)$ & $23.68(15.19)$ & $70.33(16.39)$ & $33.42(19.56)$ & $63.96(15.15)$ & $25.93(14.70)$ \\
\hline Outgroup & $45.89(19.57)$ & $39.50(20.94)$ & $58.50(20.02)$ & $39.52(22.05)$ & $56.27(16.16)$ & $33.62(19.52)$ \\
\hline \multicolumn{7}{|l|}{ Low status } \\
\hline Ingroup & $56.43(18.44)$ & $30.81(19.58)$ & $69.06(16.56)$ & $35.07(20.76)$ & $62.46(14.39)$ & $27.00(17.86)$ \\
\hline Outgroup & $67.33(17.00)$ & $27.51(16.35)$ & $68.68(15.41)$ & $39.16(21.34)$ & $57.47(13.74)$ & $32.13(18.11)$ \\
\hline \multicolumn{7}{|c|}{ Trait similarity measure } \\
\hline \multicolumn{7}{|l|}{ High status } \\
\hline Ingroup & $5.15(1.28)$ & $3.80(1.58)$ & $5.19(1.11)$ & $3.76(1.48)$ & $4.69(1.18)$ & $3.54(1.48)$ \\
\hline Outgroup & $4.19(1.41)$ & $4.17(1.45)$ & $4.49(1.30)$ & $3.99(1.43)$ & $4.46(1.26)$ & $4.04(1.50)$ \\
\hline \multicolumn{7}{|l|}{ Low status } \\
\hline Ingroup & $4.28(1.38)$ & $3.97(1.53)$ & $5.00(1.31)$ & $3.91(1.50)$ & $4.56(1.27)$ & $3.71(1.57)$ \\
\hline Outgroup & $5.00(1.31)$ & $4.00(1.55)$ & $5.03(1.26)$ & $4.02(1.39)$ & $4.48(1.21)$ & $3.93(1.43)$ \\
\hline
\end{tabular}

Notes: Standard deviations are in parentheses. Sample size is 149 for high status and 149 for low status for the mean and percent estimate measures and 149 for high status and 147 for low status for the trait similarity measure. Higher numbers indicate that a given trait is perceived to be (a) more descriptive of the group for the mean measure,

(b) possessed by a greater percentage of group members for the percent estimate measure, and (c) shared to a greater extent as a basis of similarity among group members for the similarity measure.

the group effect in levels of valence indicated that members of the low status group acknowledged the status differential and considered the outgroup relative to the ingroup to be better described by the positive status traits $(F(1,148)$ $=49.28, p<.01)$. Concurrently, however, they evidenced a strategic process of intergroup comparison on the irrelevant traits by rating the positive irrelevant traits as more descriptive of the ingroup than the outgroup $(F(1,148)=$ $14.88, p<.01)$, and the negative irrelevant traits as more descriptive of the outgroup than the ingroup $(F(1,148)=14.97, p<.01)$.

Percent estimate measure The predicted Status $\times$ Group $\times$ Relevance $\times$ Valence four-way interaction was significant $(F(2,289)=67.29, p<$ $.01)$. The middle panel of Table 3 displays the relevant means. The Group $\times$ Relevance $\times$ Valence effect was significant for the high status group $(F(2,147)=44.53, p<.01)$, and low status group $(F(2,147)=25.58, p<.01)$.

For the high status group, the Group $\times$ Valence interaction was significant for the status traits $(F(1,148)=147.58, p<.01)$, power traits $(F(1,148)=36.16, p<.01)$, and irrelevant traits $(F(1,148)=40.05, p<.01)$. Tests of the group effect in levels of valence indicated that members of the high status group perceived a greater percentage of ingroup than outgroup members possessed the positive status traits $(F(1,148)=170.37, p<.01)$, positive power traits $(F(1,148)=47.08, p<.01)$, and positive irrelevant traits $(F(1,148)=27.00, p<.01)$. On the other hand, they perceived a greater percentage of outgroup than ingroup members 
possessed the negative status traits $(F(1,148)=$ $77.91, p<.01)$, negative power traits $(F(1,148)$ $=14.71, p<.05)$, and negative irrelevant traits $(F(1,148)=34.63, p<.01)$.

For the low status group, the Group $\times$ Valence interaction was significant for the status traits $(F(1,148)=21.72, p<.01)$ and irrelevant traits $(F(1,148)=23.82, p<.01)$. Tests of the group effect in levels of valence indicated that members of the low status group acknowledged the status difference and perceived a greater percentage of outgroup than ingroup members possessed the positive status traits $(F(1,148)=28.53, p<.01)$ and a greater percentage of ingroup than outgroup members possessed the negative status traits $(F(1,148)=$ $5.66, p<.05)$. At the same time, they evidenced a strategic process of intergroup comparison and perceived the positive irrelevant traits to be possessed by a greater percentage of ingroup than outgroup members $(F(1,148)=17.68, p<$ $.01)$, and the negative irrelevant traits to be possessed by a greater percentage of outgroup than ingroup members $(F(1,148)=15.49, p<$ $.01)$.

Trait similarity measure ${ }^{4}$ The predicted Status $\times$ Group $\times$ Relevance $\times$ Valence four-way interaction was significant $(F(2,287)=17.72$, $p<.01)$. The bottom panel of Table 3 displays the relevant means. The Group $\times$ Relevance $\times$ Valence effect was significant for the high status group $(F(2,147)=5.10, p<.01)$, and low status group $(F(2,145)=14.26, p<.01)$.

For the high status group, the Group $\times$ Valence interaction was significant for the status traits $(F(1,148)=44.93, p<.01)$, power traits $(F(1,148)=25.89, p<.01)$, and irrelevant traits $(F(1,148)=20.52, p<.01)$. Tests of the group effect in levels of valence indicated that members of the high status group perceived more similarity among members of the ingroup than outgroup on the positive status traits $(F(1$, $148)=55.74, p<.01)$, positive power traits $(F(1$, $148)=30.64, p<.01)$, and positive irrelevant traits $(F(1,148)=4.47, p<.01)$. On the other hand, they perceived more similarity among members of the outgroup than ingroup on the negative status traits $(F(1,148)=8.12, p<.01)$, and negative irrelevant traits $(F(1,148)=20.15$, $p<.01)$.

For the low status group, the Group $\times$ Valence interaction was significant for the status traits $(F(1,146)=17.79, p<.01)$, and irrelevant traits $(F(1,146)=4.45, p<.05)$. Tests of the group effect in levels of valence indicated that members of the low status group acknowledged the status difference and perceived more similarity among members of the outgroup than ingroup on positive status traits $(F(1,146)$ $=39.75, p<.01)$. Simultaneously, however, they evidenced a strategic process of intergroup comparison and perceived more similarity among members of the outgroup than ingroup on the negative irrelevant traits $(F(1,146)=$ $3.98, p<.05)$. The means also suggested a nonsignificant tendency for members of low status groups to perceive the ingroup as more similar than the outgroup on positive irrelevant traits.

Range measure The range did not detect the predicted four-way interaction $(F(2,288)=1.51$, $n s)$. Instead, the range yielded a Group $\times$ Relevance $\times$ Status effect $(F(2,288)=4.25, p<$ $.05)$. Table 4 displays the relevant means. The Group $\times$ Relevance interaction was significant for members of the low status group $(F(2,147)$ $=4.01, p<.05)$ but not for members of the high status group $(F(2,146)=.70, n s)$. Pairwise comparisons indicated that members of low status groups perceived a greater range among ingroup vs. outgroup members (i.e. outgroup homogeneity) on only the status traits $(F(1,148)$ $=10.11, p<.01)$. Participants did not perceive intergroup differences on the other traits.

Additionally, the range yielded a Group $\times$ Relevance $\times$ Power effect $(F(2,288)=3.33, p<$ $.05)$. Table 5 displays the relevant means. The Group $\times$ Relevance interaction was significant for members of the high power group $(F(2$, $146)=3.32, p<.05)$, but not for members of the low power group $(F(2,147)=.53, n s)$. Pairwise comparisons indicated that members of high power groups perceived a greater range among ingroup vs. outgroup members (i.e. outgroup homogeneity) on only the status traits $(F(1,147)$ $=6.44, p<.05)$. Participants did not perceive intergroup differences on the other traits. 
Boldry E Gaertner STATUS AND INTERgROUP PERCEPTION

Table 4. Mean range perception (and standard deviations) as a function of group, relevance, and status

\begin{tabular}{lccc}
\hline Status & Status relevant & Power relevant & Irrelevant \\
\hline High status & & & \\
$\quad$ Ingroup & $3.83(1.13)$ & $3.87(1.12)$ & $3.92(1.15)$ \\
$\quad$ Outgroup & $3.90(1.15)$ & $3.89(1.23)$ & $3.92(1.25)$ \\
Low status & & & $3.93(1.22)$ \\
$\quad$ Ingroup & $4.03(1.15)$ & $3.77(1.14)$ & $3.85(1.17)$ \\
Outgroup & $3.82(1.14)$ & $3.73(1.19)$ & \\
\hline
\end{tabular}

Notes: Standard deviations are in parentheses. Sample size for high status groups varies from 148-149 (due to missing data) and for low status groups is 149 . Higher numbers indicate a greater perceived range among group members.

Factor analysis As we speculated in the discussion of Experiment 1, the percent estimate measure may reflect perceptions of central tendency rather than variability. Consequently, we included a measure of similarity to tap perceptions of intergroup variability. Indeed an exploratory factor analysis demonstrated that percent estimate and mean together reflect a construct different than that of similarity. In particular, we conducted an exploratory factor analysis using varimax rotation. We treated ingroup and outgroup ratings as separate indicators of each measure. All criteria for determining the number of factors to retain (i.e. eigenvalues, scree plot, and proportion of variance explained) unambiguously indicated the retention of three factors. Table 6 contains the factor loadings from the rotated factor pattern matrix. The factor pattern matrix, which reflects the variance in each item that is uniquely contributed by each factor, indicates that the mean and percent estimate measures have strong loadings on Factor 1 and near zero loadings on Factors 2 and 3. The range measure has strong loadings on Factor 2 and near zero loadings on Factors 1 and 3. The trait similarity measure has strong loadings on Factor 3 and near zero loadings on Factors 1 and 2.

\section{Discussion}

Consistent with our speculation, the factor analysis indicated that the similarity measure tapped a construct distinct from that of the mean and percent estimate. Nevertheless, the mean, percent estimate, and similarity measures detected the same four-way interaction detected in the previous experiment. The pattern of the interaction was consistent with SIT's strategic intergroup comparison account and was not moderated by power. Members of both status groups acknowledged the status hierarchy on the positive status traits

Table 5. Mean range perception (and standard deviations) as a function of group, relevance, and power

\begin{tabular}{lccc}
\hline Power & Status relevant & Power relevant & Irrelevant \\
\hline High power & & & \\
$\quad$ Ingroup & $3.90(1.20)$ & $3.77(1.20)$ & $3.85(1.21)$ \\
Outgroup & $3.75(1.20)$ & $3.78(1.27)$ & $3.83(1.27)$ \\
Low power & $3.96(1.09)$ & $3.87(1.07)$ & $4.00(1.15)$ \\
Ingroup & $3.97(1.08)$ & $3.84(1.15)$ & $3.94(1.14)$ \\
Outgroup & & & \\
\hline
\end{tabular}

Notes: Standard deviations are in parentheses. Sample size is 148 for high power groups and varies between 149-150 (due to missing data) for low power groups. Higher numbers indicate a greater perceived range among group members. 
Table 6. Factor loadings for the iintergroup perception measures from the rotated factor pattern

\begin{tabular}{lccr}
\hline & \multicolumn{3}{c}{ Factor pattern } \\
\cline { 2 - 4 } Item & Factor 1 & Factor 2 & Factor 3 \\
\hline Mean-Ingroup & $\mathbf{5 4}$ & .01 & .16 \\
Mean-Outgroup & $\mathbf{. 5 9}$ & -.01 & -.02 \\
Percent Estimate-Ingroup & $\mathbf{. 7 6}$ & .06 & -.12 \\
Percent Estimate-Outgroup & $\mathbf{. 7 3}$ & .01 & $\mathbf{1 . 0 1}$ \\
Trait Similarity-Ingroup & .03 & -.04 & -.13 \\
Trait Similarity-Outgroup & .03 & -.07 & -.01 \\
Range-Ingroup & .03 & $\mathbf{8 5}$ & $\mathbf{1 . 0 0}$ \\
Range-Outgroup & .01 & & \\
\hline
\end{tabular}

as such that they perceived those traits to be more descriptive of, possessed by a greater percentage of, and a stronger basis of similarity among members of the high than low status group. Only members of the high status group acknowledged the status differential on the negative status traits by perceiving those traits to be more descriptive of, possessed by a greater percentage of, and a stronger basis of similarity among members of the low than high status group.

Members of both groups evidenced ingroup favoring perceptions on the positive and negative irrelevant traits. They perceived the positive irrelevant traits to be more descriptive of, possessed by a greater percentage of, and a stronger basis of similarity among ingroup than outgroup members and perceived the negative traits to be more descriptive of, possessed by a greater percentage of, and a stronger basis of similarity among outgroup than ingroup members. As in the previous experiment, only members of the high status group further enhanced the social value of the ingroup on the power relevant traits. In particular, members of the high status group perceived the positive power traits to be more descriptive of, possessed by a greater percentage of, and as having a stronger basis of similarity among ingroup than outgroup members and perceived the negative status traits to be more descriptive of and possessed by a greater percentage of ingroup than outgroup members.

As in the previous experiment, the range measure did not detect the predicted four-way interaction. The range did detect a theoretically ambiguous Group $\times$ Relevance $\times$ Status effect and a Group $\times$ Relevance $\times$ Power effect, such that members of high status groups and members of high power groups are particularly apt to perceive a greater range among ingroup than outgroup members on status relevant traits regardless of the valence of those traits. Although, it is plausible that the patterns of the range are meaningful, the ambiguity of those patterns and their inconsistency across studies implies a degree of spuriousness.

Finally, readers might wonder whether an intergroup payoff asymmetry provides an alternative explanation of our data. In particular, the rational choice for both groups on the power matrix of the current experiment (see Figure 1) is the Y choice, in which members of the high and low power groups receive US $\$ 0.75$ and US $\$ 0.35$, respectively. So, in addition to having greater fate control over the low power group, the high power group receives a larger payoff when both groups select the rational choice. Experiment 1, however, eliminates the viability of an intergroup payoff asymmetry explanation. Experiments 1 and 2 evidenced the same four-way interaction derived from social identity theory and in no instance did power (or interdependence) moderate that effect. Importantly, ingroup and outgroup members in Experiment 1 received the same amount of money when both groups selected the rational choice (also, the Y choice): US $\$ 0.75$ and US $\$ 0.75$ in the independent condition and US $\$ 0.45$ and US $\$ 0.45$ in the interdependent 
condition. Consequently, an intergroup payoff asymmetry cannot account for the predicted effects of Experiment 1, which Experiment 2 replicated. On that basis an intergroup payoff asymmetry is not a viable alternative explanation and we can be confident in our conclusion that relative status affects intergroup perception independently of intergroup power.

\section{General discussion}

Intergroup status and power typically covary in social environments. Such covariation poses a difficulty for a science of intergroup relations that has the goal of differentiating and explaining the multiple causes of social perception with valid process based accounts. The current research advances the intergroup literature by methodologically distinguishing the effect of status from power. We utilized two methods of distinguishing status from power. In Experiment 1 , we manipulated the relative status of two social groups and explicitly provided those groups with equivalent power. In Experiment 2, we orthogonally manipulated the groups' relative status and power. Despite their methodological differences, the two experiments yielded remarkably consistent results indicating that relative status affects intergroup perception independently of power.

\section{Evidence for a strategic intergroup comparison account of the status effect}

The design of the experiments enables us to discuss, with a degree of confidence, the process by which status affects intergroup perception. SIT suggests that low intergroup status poses a social identity threat and motivates intergroup comparison on alternative dimensions that yield a more favorable impression of the ingroup (Tajfel \& Turner, 1979). Such motivated biases often influence intergroup perception on ambiguous dimensions that lack social consensus as to which group is superior (Ellemers et al., 1997) and constrain and enhance perceived variability in a manner that promotes a positive social identity (e.g. 'all of us are not bad' or 'all of us are good'; Ellemers \& van Risjswijk, 1997; Rubin et al., 2001).
Consistent with the strategic intergroup comparison account, both experiments detected the predicted Status $\times$ Group $\times$ Relevance $\times$ Valence four-way interaction across multiple measures, including the mean, percent estimate and, perceived similarity. That is, intergroup status yielded different perceptions of the ingroup vs. outgroup and the nature of those perceptions varied as a function of the relevance and valence of the dimension of intergroup comparison.

On the positive status dimension, members of both the low and high status groups acknowledged the established status hierarchy. Members of both groups evidenced consensual perceptions and perceived the positive status traits to be more descriptive of, possessed by a greater percentage of, and a stronger basis of similarity among member of the high than low status group. Such consensual perceptions, however, were limited to the positive status dimension. Members of both the low and high status groups perceived their own group more favorably than the outgroup on the irrelevant dimension (i.e. traits that were irrelevant to the status and power tasks). Consistent with the strategic intergroup perception account, group members capitalized on the ambiguous nature of the irrelevant traits and enhanced their social identity (e.g. "We are all happier, funnier, and more athletic than are they and they are all more shallow, grumpy, and dull than are we'.).

The pattern of intergroup perception across the positive status traits and the irrelevant traits reflects what Ellemers et al. (1997) refers to as balancing social reality with group identity. On the other hand, the negative status traits may have captured an instance in which concern for group identity overwhelmed social reality. Only members of the high status group acknowledged the confirmed status difference on the negatively valenced status dimension. Members of the low status group evidenced equivalent perceptions of the ingroup and outgroup. The tendency for members of the low status group to acknowledge the status hierarchy on the positive but not the negative status traits can be explained potentially by research indicating that threat is a stronger motivator than 
enhancement (e.g. Baumeister, Bratslavsky, Finkenauer, \& Vohs, 2001; Ito, Larsen, Smith, \& Cacioppo, 1998; Kahneman \& Tversky, 1979). Acknowledging that members of the ingroup (relative to the outgroup) possess negative qualities might be more threatening than acknowledging that members of the ingroup lack positive qualities. Perceiving the ingroup and higher status outgroup equivalently on a dimension on which the groups objectively differ is certainly suggestive of an ingroup favoring perceptual bias. That is, not perceiving existent group differences is as biased as perceiving nonexistent differences (Brauer, 2001).

We did not offer predictions for the pattern of perception on the power traits because we were uncertain as to how those traits would relate to social identity concerns. From a data driven position, however, those traits merit discussion in that both experiments revealed the same pattern of intergroup perception. Members of high status groups evidenced ingroup favoring perceptions on the positive and negative power traits. ${ }^{5}$ Members of the low status group, however, evidenced equivalent intergroup perception on the positive and negative power traits. It is important to reiterate that the low and high status groups were objectively equivalent in regard to power in Experiment 1. In Experiment 2, power and status were manipulated orthogonally and the power manipulation did not qualify the patterns of perception, such that the tendency for members of the low status group to perceive equivalent intergroup perception on the power traits occurred regardless of whether the low status group was low or high in power.

So, why did members of the high status group perceive ingroup favoring differences on the power traits while members of the low status group evidenced equivalent intergroup perceptions? Perhaps a socially confirmed status difference 'boosts the confidence' of members of the higher status group and, conversely, makes members of the low status group more vigilant to the dimension of comparison. That is, a confirmed status difference might legitimize ingroup favoritism across domains of comparison for members of the high status group and, as Ellemers et al. (1997) suggest, motivate members of the low status group toward a more selective or strategic intergroup perception based on available information.

In sum, Experiments 1 and 2 provide consistent support for the strategic intergroup comparison process derived from social identity theory (Tajfel \& Turner, 1979) and empirical extensions (e.g. Ellemers et al., 1997). Furthermore, our data reiterate the importance of the relevance and valence of the dimension of intergroup comparison (e.g. Doosje, Haslam, Spears, Oakes, \& Koomen, 1998; Simon, 1992) as well as the ingroup's relative status (e.g. Doosje, Spears, \& Koomen, 1995; LorenziCioldi et al., 1998). Importantly, the current research demonstrates that relative group status affects intergroup perception (central tendency and variability) independently of power.

\section{Inconsistencies between the range and the other measures of intergroup perception}

The mean, percent estimate, and similarity evidenced the same four-way interaction. The range measure, on the other hand, neither tracked the predicted four-way interaction nor evidenced consistency across studies. Furthermore, in instances in which the range evidenced a difference in the perceived variability of the ingroup vs. outgroup, the direction of that difference was opposite to the pattern detected by the other measures (i.e. ingroup vs. outgroup homogeneity). One explanation as to why the range revealed patterns different than the other measures is that unlike the other measures, which required participants to make judgments at the group level, the range measure required participants to make judgments in regard to specific individuals (the two most extreme group members). Although this group- vs. person-level focus cannot account for the inconsistent pattern in the range across studies, it can account for the discrepancy between the range and the other measures. However, the group-level focus cannot account for all variation in perception. Indeed, the factor analysis revealed that similarity loaded on a construct different than that of the mean and percent estimate, suggesting that the strategic 
intergroup comparison mechanism of SIT affects perceptions of variability as well as central tendency.

\section{What about intergroup power?}

Both experiments consistently indicated that status affects intergroup perception independent of power. Aside from the Group $\times$ Relevance $\times$ Power effect detected by the range measure in Experiment 2, the power manipulations had no apparent effect on the dependent measures. So, what should we conclude about the effect of power?

It is noteworthy that the checks for the power manipulations were significant and in the intended direction. In Experiment 1, in which we attempted to equate the relative power of the ingroup and outgroup, participants attributed equal power to the ingroup and outgroup and, as we intended, perceived both groups as being more powerful in the interdependent than independent condition. In Experiment 2, in which we manipulated relative group power, participants attributed less power to the ingroup vs. outgroup in the low power condition and more power to the ingroup vs. outgroup in the high power condition. Furthermore, the effect of relative group power was descriptively large. The effect size $(d)$ in Experiment 2 for the manipulation of relative power on the perceived power of the ingroup vs. outgroup was 1.39 (with a 95\% confidence interval of 1.26 to 1.51 ). Consequently, the argument for a weak or failed manipulation cannot explain the relatively nonexistent effect of power on the measures of mean, percent estimate, similarity, and range.

Given the sufficient manipulations of power and their minimal effects on intergroup perception, some readers might conclude that intergroup power does not affect perception. We strongly caution that our methodology does not warrant such a conclusion. We intentionally restricted the information participants received about ingroup and outgroup members to differentiate the effects of status from power on intergroup perception. As we previously discussed, intergroup power is argued to affect perception either directly by increasing attention to outgroup members (e.g. Fiske, 1993) or indirectly, by constraining the actual behavioral diversity of low status groups and yielding a homogeneous pool of information about those groups (Guinote et al., 2002). Because we did not provide idiosyncratic characteristics of ingroup and outgroup members, the experimental context was not sensitive to potential power effects and it is not appropriate to conclude that intergroup power does not affect perception. The current research does demonstrate, however, that status affects perception independent of power via a strategic intergroup comparison process.

\section{Perceiver status and target status}

Often it is difficult to interpret effects of intergroup status in paradigms employing only two social groups (Brauer, 2001). In such a paradigm, status is asymmetrical (one group is high in status and the other is low) and it is not immediately obvious whether a status effect is due to the status of the perceiver (i.e. being in a low or high status group) or the target (i.e. perceiving a low or high status group). A target effect produces consensual intergroup perceptions among members of both groups. For example, when the low status group perceives outgroup homogeneity and the high status group perceives ingroup homogeneity the perceptions are consensual in that members of both groups perceive less variability in the high status group. A perceiver effect, on the other hand, produces divergent perceptions between members of both groups. That is, members of both groups disagree as to which group is more or less variable.

By assessing intergroup perception on multiple dimensions of comparison we obtained patterns consistent with both perceiver and target effects. We obtained consensual perceptions on the positive status traits such that members of both groups acknowledged the status advantage of the high than low status group. On the remaining traits (i.e. negative status, positive and negative power, and positive and negative irrelevant) we obtained divergent perceptions between members of the low and high status groups. The apparent target effect 
on the positive status traits was driven by the confirmed status difference such that members of both groups were aware of the status hierarchy. However, the divergent patterns of perception on the negative status traits suggest that a target effect does not invariantly result from existing group differences. Further attention should be directed at contextual and intrapsychic factors that generate target and perceiver effects (e.g. Brauer, 2001).

\section{Caveat}

A limitation of the current research is that status and power were not manipulated at the same perceptual level. Specifically, relative group status was presented to participants as a global property of the ingroup and outgroup (e.g. Klees typically score better than Kandinskys), whereas relative group power was presented as specific to the experimental situation. Consequently, it may be that conclusions from the present research are generalizable only to intergroup contexts in which group status is global and group power is situational. Future research should explore the boundaries of these effects in alternate intergroup contexts (e.g. Christensen, Boldry, \& Kashy, 2004).

\section{Conclusion}

The current research methodologically distinguished intergroup status from power and revealed that intergroup status affects intergroup perceptions independently of power. Furthermore, the strategic intergroup comparison process of social identity theory provides a viable explanation for the status effect in that the patterns of intergroup perception varied as a function of the relevance and valence of the dimension of intergroup comparison in a manner that balanced the constraints of social reality with a drive toward a positive social identity.

\section{Notes}

1. Group size covaries with status and power and certainly contributes to interpretational difficulties. We control for relative group size by holding it constant and explicitly informing participants that the groups consist of an equal number of members. Past research has differentiated the effects of relative group status and size by orthogonally manipulating those factors (Ellemers \& Van Rijswijk, 1997) or by holding size constant and manipulating status (Lorenzi-Cioldi, Eagly, \& Stewart, 1995). Those studies did not differentiate status and power.

2. We planned to use a distribution task that measures the probability of differentiation (Pd; Linville, Fischer, \& Salovey, 1989). However, pilot testing indicated that the distribution task provided a Pd measure with extremely low internal consistency and doubled the time required to complete the session. An experience consonant with Park and Judd's (1990) observation that, 'subjects sometimes have difficulty completing the distribution task' (p. 175).

3. We considered treating positive traits as stereotype consistent and negative traits as stereotype inconsistent to construct a measure of percent estimate similar to those used in previous research. However such an approach was not possible with the irrelevant traits, and, more importantly would prevent us from examining the Group $\times$ Status $\times$ Relevance $\times$ Valence interaction predicted by social identity theory.

4. We do not have responses to the trait similarity measure for two participants.

5. The one exception being the perception of the ingroup and outgroup on the negative traits with the similarity measure in Experiment 2. Although the direction of the means was consistent with the pattern on the other measures, the difference was not statistically significant.

\section{Acknowledgment}

Experiment 1 comprised a portion of the first author's doctoral dissertation, which the second author directed.

\section{References}

Bardach, L., \& Park, B. (1996). The effect of in-group and out-group status on memory for consistent and inconsistent behavior of an individual. Personality and Social Psychology Bulletin, 22, 169-178.

Barth, E. A., \& Noel, D. L. (1972). Conceptual frameworks for the analysis of race relations: An evaluation. Social Forces, 50, 333-348. 
Baumeister, R. F., Bratslavsky, E., Finkenauer, C., \& Vohs, K. D. (2001). Bad is stronger than good. Review of General Psychology, 5, 323-370.

Bettencourt, B. A., Dorr, N., Charlton, K., \& Hume, D.L. (2001). Status differences and ingroup bias: A meta-analytic examinations of the effects of status stability, status legitimacy, and group permeability. Psychological Bulletin, 127, 520-542.

Boldry, J. G., \& Kashy, D. A. (1999). Intergroup perception in naturally occurring groups of differential status: A social relations perspective. Journal of Personality and Social Psychology, 77, 1200-1212.

Brauer, M. (2001). Intergroup perception in the social context: The effects of social status and group membership on perceived out-group homogeneity and ethnocentrism. Journal of Experimental Social Psychology, 37, 15-31.

Brewer, M. B. (1979). Ingroup bias in the minimal intergroup situation: A cognitive-motivational analysis. Psychological Bulletin, 86, 307-334.

Brown, R., \& Wootten-Millward, L. (1993). Perceptions of group homogeneity during group formation and change. Social Cognition, 11, 126-149.

Cabecinhas, R., \& Amancio, L. (1999). Asymmetries in the perception of others as a function of social position and context. Swiss Journal of Psychology, 58, 40-50.

Carli, L. L, \& Eagly, A. H. (1999). Gender effects on social influence and emergent leadership. In G. N. Powell (Ed.), Handbook of gender and work (pp. 203-222). Thousand Oaks, CA: Sage.

Christensen, P. N., Boldry, J. G., \& Kashy, D. A. (2004). Group-based self-evaluation outside the laboratory: Effects of global versus contextual status. Personality and Social Psychology Bulletin, 30, 985-994.

Doosje, B., Haslam, S. A., Spears, R., Oakes, P. J., \& Koomen, (1998). The effect of comparative context on central tendency and variability judgments and the evaluation of group characteristics. European Journal of Social Psychology, 28, 173-184.

Doojse, B., Spears, R., \& Koomen, W. (1995). When bad isn't all bad: Strategic use of sample information in generalization and stereotyping. Journal of Personality and Social Psychology, 69, 642-655.

Ellemers, N., Van Knippenberg, A., De Vries, N., \& Wilke, H. (1988). Social identification and permeability of group boundaries. European Journal of Social Psychology, 18, 497-413.

Ellemers, N., Van Knippenberg, A., \& Wilke, H.
(1990). The influence of permeability of group boundaries and stability of group status on strategies of individual mobility and social change. British Journal of Social Psychology, 29, 233-246.

Ellemers, N., \& Van Rijswijk, W. (1997). Identity needs versus social opportunities: The use of group-level and individual-level identity management strategies. Social Psychology Quarterly, $60,52-65$.

Ellemers, N., Van Rijswijk, W., Roefs, M., \& Simons, C. (1997). Bias in intergroup perceptions: Balancing group identity with social reality. Personality and Social Psychology Bulletin, 23, 186-198.

Fiske, S. T. (1993). Controlling other people: The impact of power on stereotyping. American Psychologist, 48, 621-628.

Fiske, S. T., \& Depret, E. (1996). Control, interdependence, and power: Understanding social cognition in its social context. In W. Stroebe \& M. Hewstone (Eds.), European Review of Social Psychology (Vol. 7, pp. 31-61). Chichester, UK: Wiley.

Guinote, A., Judd, C. M., \& Brauer, M. (2002). Effects of power on perceived and objective group variability: Evidence that more powerful groups are more variable. Journal of Personality and Social Psychology, 82, 708-721.

Hall, J. (1971, November). Decisions, decisions, decisions. Psychology Today, 51-54 and 86-88.

Hewstone, M., Rubin, M., \& Willis, H. (2002). Intergroup bias. Annual Review of Psychology, 53, 575-604.

Ito, T. A., Larsen, J. T., Smith, N. K., \& Cacioppo, J. T. (1998). Negative information weighs more heavily on the brain: The negativity bias in evaluative categorizations. Journal of Personality and Social Psychology, 75, 887-900.

Kahneman, D., \& Tversky, A. (1979). Prospect theory: An analysis of decision under risk. Econometrica, 47, 263-291.

Kelley, H. H., \& Thibaut, J. W. (1978). Interpersonal relations: A theory of interdependence. New York: Wiley Interscience.

Linville, P. W., Fischer, G. W., \& Salovey, P. (1989). Perceived distributions of the characteristics of in-group and out-group members: Empirical evidence and a computer simulation. Journal of Personality and Social Psychology, 57, 165-188.

Lorenzi-Cioldi, F. (1993). They all look alike and so do we ... sometimes: Perceptions of in-group and out-group homogeneity as a function of sex and context. British Journal of Social Psychology, 32, 111-124. 
Lorenzi-Cioldi, F. (1998). Group status and perceptions of homogeneity. In Stroebe, W. and Hewstone, M. (Eds.), European Review of Social Psychology, 9, 31-75. New York: John Wiley and Sons.

Lorenzi-Cioldi, F., Deaux, K., \& Dafflon, A. (1998). Group homogeneity as a function of relative social status. Swiss Journal of Psychology, 57, 255-273.

Lorenzi-Cioldi, F., Eagly, A. H., \& Stewart, T. (1995). Homogeneity of gender groups in memory. Journal of Experimental Social Psychology, 31, 193-217.

Mullen, B., Brown, R., \& Smith, C. (1992). Ingroup bias as a function of salience, relevance, and status: An integration. European Journal of Social Psychology, 22, 103-122.

Neuberg, S. L., \& Fiske, S. T. (1987). Motivational influences on impression formation: Outcome dependency, accuracy driven attention, and individuating processes. Journal of Personality and Social Psychology, 53, 431-444.

Park, B., \& Judd, C. M. (1990). Measures and models of perceived group variability. Journal of Personality and Social Psychology, 59, 173-191.

Park, B., \& Rothbart, M. (1982). Perception of out-group homogeneity and levels of social categorization: Memory for the subordinate attributes of in-group and out-group members. Journal of Personality and Social Psychology, 42, 1051-1068.

Quattrone, G. A., \& Jones, E. E. (1980). The perception of variability within in-groups and out-groups: Implications for the law of small numbers. Journal of Personality and Social Psychology 38, 141-152.

Rubin, M., Hewstone, M., \& Voci, A. (2001). Stretching the boundaries: Strategic perceptions of intragroup variability. European Journal of Social Psychology, 31, 413-429.

Sachdev, I., \& Bourhis, R. Y. (1991). Power and status differentials in minority and majority group relations. European Journal of Social Psychology, 21, $1-24$.

Sedikides, C. (1997). Differential processing of ingroup and outgroup information: The role of relative group status in permeable boundary groups. European Journal of Social Psychology, 27, 121-144.

Sidanius, J., \& Pratto, F. (1999). Social dominance: An intergroup theory of social hierarchy and oppression. Cambridge, UK: Cambridge University Press.

Simon, B. (1992). Intragroup differentiation in terms of ingroup and outgroup attributes. European Journal of Social Psychology, 22, 407-413.

Tajfel, H., Billig, M., Bundy, R. P., \& Flament, C. (1971). Social categorization and intergroup behaviour. European Journal of Social Psychology, 1, 149-178.

Tajfel H., \& Turner, J. C. (1979). An integrative theory of intergroup conflict. In S. Worchel, \& W. G. Austin (Eds.), The social psychology of intergroup relations (pp. 33-47). Monterey, CA: Brooks/Cole.

Paper received 29 September 2004; revised version accepted 14 April 2005.

\section{Biographical notes}

JENNIFER G. BOLDRY received her PhD in social psychology at Texas A\&M University in 2001. Her main areas of research include intergroup and interpersonal perception, particularly with respect to the effects of status and power.

LOWELL GAERTNER is an assistant professor of psychology at the University of Tennessee. In addition to his interests in intergroup and intragroup relations, he studies self processes and mass violence. 